\title{
National General Health Screening Program in Korea: history, current status, and future direction
}

\section{A scoping review}

\section{Dong Wook Shin ${ }^{1,2,3}$, Juhee Cho ${ }^{2,3}$, Jae Hyun Park ${ }^{4}$, BeLong Cho ${ }^{5}$}

${ }^{1}$ Department of Family Medicine/Supportive Care Center, Samsung Medical Center, Sungkyunkwan University School of Medicine, Seoul, Korea

${ }^{2}$ Department of Clinical Research Design \& Evaluation, Samsung Advanced Institute for Health Sciences \& Technology,

Sungkyunkwan University, Seoul, Korea

${ }^{3}$ Department of Digital Health, Samsung Advanced Institute for Health Sciences \& Technology, Sungkyunkwan University, Seoul, Korea

${ }^{4}$ Department of Social Medicine, Sungkyunkwan University School of Medicine, Seoul, Korea

${ }^{5}$ Department of Family Medicine, Seoul National University Hospital, Seoul National University College of Medicine, Seoul, Korea

Received: October 6, 2021

Revised: December 28, 2021

Accepted: January 10, 2022

Corresponding author:

Dong Wook Shin

Department of Family Medicine/

Supportive Care Center, Samsung

Medical Center, Sungkyunkwan

University School of Medicine,

81 Irwon-ro, Gangnam-gu, Seoul

06351, Korea

Tel: +82-2-3410-5252

E-mail:dwshin@skku.edu

\section{ABSTRACT}

Health screening is an important component of health promotion programs, and countries have promoted general health screening targeting the prevention and early management of common chronic diseases. In Korea, a General Health Screening Program (GHSP) began with workers in the 1950s and continuously expanded its target population, and currently includes the adult population. The main target diseases are cerebroand cardiovascular diseases, including hypertension, diabetes mellitus, dyslipidemia, obesity, and related health behaviors. Other target conditions include other diseases (e.g., anemia, liver disease, visual/auditory impairment), mental health (e.g., depression), and geriatric disease and function (osteoporosis, dementia, risk of fall, etc.). The National Health Information Database, including GHSP information, is now extensively used in clinical and public health research. The participation rate is currently $70 \%$ to $80 \%$, but varies according to age, disability, and the socioeconomic status. There is a need for a more systematic evaluation of the screening items, reducing disparity gaps in participation, and linking GHSP to actual health promotion.

Keywords: Cardiovascular diseases; Health check; Health screening; Korea; National health programs
This is an Open Access article distributed under the terms of the Creative Commons Attribution Non-Commercial License (https:// creativecommons.org/licenses/ by-nc/4.0/). 


\section{INTRODUCTION}

Health screening is an application of a test to detect a disease or conditions early when they are easier to manage and is considered as secondary prevention of disease. It is an important component of health promotion programs and has the potential to prevent morbidity and mortality.

Thus, countries have promoted general health screening targeting the prevention and early management of common chronic diseases, such as hypertension [1], diabetes mellitus [2], dyslipidemia [3], and screening for other specific diseases, such as osteoporosis [4], depression [5], chronic hepatitis $B$ and $C[6,7]$, and latent tuberculosis [8] at least in the highrisk group.

In the United States, under the Affordable Care Act, health plans are required to cover a set of preventive services, including health screening at no cost; additionally, Medicare provides annual wellness visits, which include health assessments and counseling [9]. In 2011, the United Kingdom implemented a national health check program targeting cardiovascular disease and diabetes in adults aged 40 to 74 years $[10,11]$. Japan has mandated health check-ups for all employees under the Industrial Safety and Health Act of 1972, and introduced a new National Health Screening Program (NHSP) called 'Specific Health Checkup' in 2008, which focuses on preventing metabolic syndrome and provided annually to people aged 40 to 74 years [12].
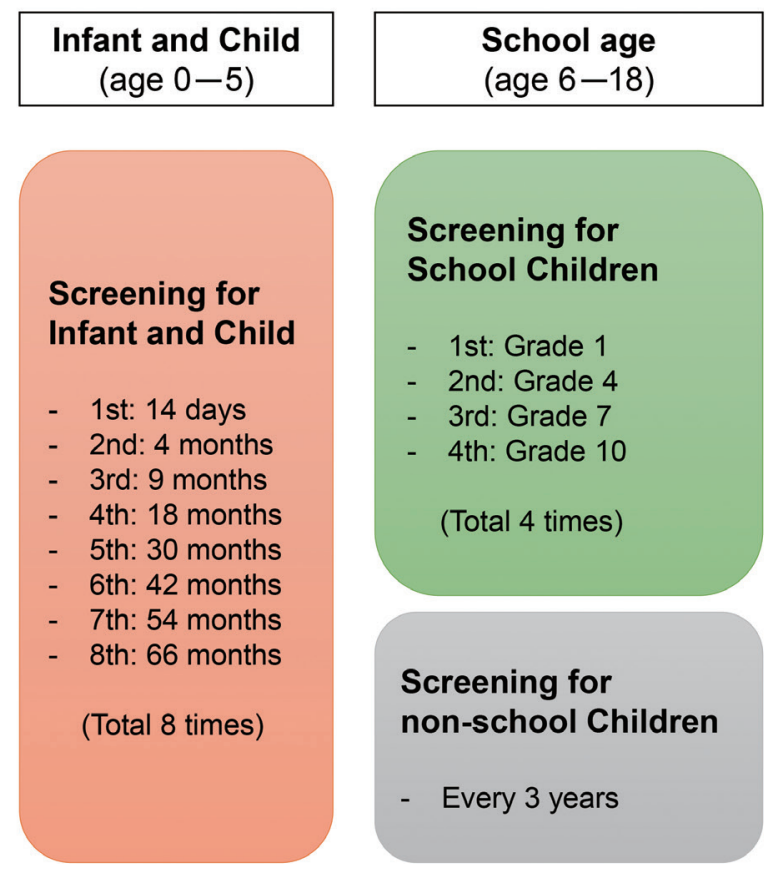

In Korea, health screening programs for chronic diseases began quite early, from the year 1980. It has continuously changed with changing societal health demands, expanding the target population, target diseases, and health screening items, and various policy measures have been implemented to improve the effectiveness and reduce disparity. Data from the NHSP are currently used not only for domestic health policy purposes, but also for research purposes [13].

Currently, the NHSP in Korea is the world's largest health screening program. However, the references for this program are rarely available in English. In this article, we have attempted to provide a brief overview of the National General Health Screening Program (GHSP), which is the main part of the NHSP. While the overall NHSP encompasses a wide range of health screening, including screening for infants and children [14], adolescents at school age [15], cancer screening [16], etc. (Fig. 1), they were not covered in this article and references can be found elsewhere.

\section{BASICS OF KOREAN HEALTHCARE SYSTEM}

\section{Brief history of the national health care system in Korea}

To better understand the NHSP in Korea, an understanding of the basics of the Korean healthcare system is necessary. Korea became an independent country in 1945 after World War

\begin{tabular}{|c|}
\hline $\begin{array}{c}\text { Adult age } \\
\text { (age } \geq 19)\end{array}$ \\
\hline
\end{tabular}

Other diseases: anemia, tuberculosis, liver disease, hepatitis B,

\section{General Health Screening Program}

- Cardiovascular risk factors: hypertension, diabetes mellitus, dyslipidemia, health behaviors

- Mental health: depression

- Geriatric disease and function: osteoporosis, dementia, risk of fall

- Every 2 years (every years for manual laborer)

\section{National Cancer Screening Program}

- Stomach cancer: age $\geq 40$, every 2 years

- Liver cancer: age $\geq 40$, high risk group, every 6 months

- Colon cancer: age $\geq 50$, every year

- Breast cancer: age $\geq 40$, every 2 years

- Cervical cancer: age $\geq 20$, every 2 years

- Lung cancer: age 54-74, high risk group, every 2 years

Fig. 1. Overview of National Health Screening Program in Korea. 
II and experienced the Korean War during the period 1950 to 1953.

In 1963, Korea implemented its first law on health insurance, called 'the Medical Insurance Act,' which allowed companies to provide voluntary health insurance to its employees. In 1977, the 'National Health Insurance Act' mandated medical insurance in large corporations (with 500 or more employees), and its coverage was expanded to public workers in 1979, and thereafter to workers in smaller companies. Finally, self-employed individuals (small business owners, farmers, fishermen, etc.) were included in 1989, achieving universal coverage only 12 years after the initiation. However, during the process, more than 350 different health insurance societies were produced, leading to inefficiency. In 2000, the National Health Insurance Service (NHIS) was established by merging all health insurances into a single national health insurer with uniform insurance schemes and benefit packages $[17,18]$.

In brief, the Korean National Health Insurance (KNHI) and Medical Aid Program (MAP) comprise the health security system in Korea. As of April 2020, from the approximately 52 million population, $70.5 \%$ was 'employee insured (or workplace policy holder),' $26.7 \%$ was 'self-employee insured (or regional policyholder),' and $2.8 \%$ was MAP recipient [19].

The KNHI is a mandatory social health insurance, and its contribution is based on the income level, independent of age, other health risks, and the number of dependent family members (spouse, linear ascendants, and linear descendants). Salaried workers (employees of workplaces, public officials, and school employees) pay around $7 \%$ of their total income as insurance premiums, and they and their dependent family members are considered as 'employee insured' (or workplace policy holder). Self-employees (and those who have incomes including pension above a certain level, etc.) contribute insurance premiums based on their income and assets (e.g., price of their house and car), and they and their dependent family members are called self-employee insured (or regional policy holder). Currently, approximately $97 \%$ of the Korean population are subscribers to the KNHI.

The remaining 3\% in the lowest income bracket (households with $<40 \%$ of median family income) cannot contribute any insurance premium, and are covered by the MAP, a public assistance program funded by government subsidies to provide low-income groups with healthcare services. MAP beneficiaries are not insurance subscribers; NHIS manages all administrative processes for them and reimburses medical providers and pharmacies based on their service provid- ed to MAP recipients.

The benefits of the NHIS are uniform and do not vary by the contribution level. It comprises of 'benefits in kind' and 'benefits in cash.' The benefits in kind include health care benefits (i.e., prescription, treatment, surgery, rehabilitation treatment, nursing, hospitalization for diseases, injuries, and births) and health check-ups (i.e., NHSP). The benefits in cash include: (1) reimbursement of expenses under the copayment ceiling system (for details, see the following section); (2) assistive appliance expenses for the disabled (e.g., walking sticks/canes, wheelchairs, and hearing aids); and (3) pregnancy examination and childbirth expenses. Additional general information and details on the Korean health systems and the KNHI can be found elsewhere [18,20]. An English version of the National Health Insurance Act can be found at the Korea Law Translation Center (https://elaw.klri.re.kr/kor_service/lawView. do?hseq= 53994\&lang=ENG).

\section{Operational structure}

The Ministry of Health and Welfare plays a central role in health planning, policy formulation, and policy implementation at the national level [18]. They oversee the KNHI system but delegate the role of running it to two quasi-public corporations: the NHIS and Health Insurance Review and Assessment Service (HIRA). The NHIS manages the eligibility of the insured, collects the insurance premiums, pools the risk, manages the funds, and reimburses the providers. HIRA reviews the claims from the provider, assesses the appropriateness of service, and provides technical support for quality improvement, such as drug utilization review (Fig. 2) [18].

\section{Healthcare delivery}

In contrast to the public nature of health financing systems, healthcare delivery in Korea relies largely on the private sector [21]. Healthcare providers are mostly private: approximately $90 \%$ of the hospitals are privately owned, and approximately two-thirds of higher-level hospitals are run by private universities. There is no direct government subsidy for private hospitals. Primary care clinics are mostly owned by a single physician or a group of physicians. Public hospitals are mainly established by the local government; however, their revenue is mainly from the reimbursement of the KNHI based on their service provision, and there are some subsidies from the government. Public health centers funded by the local government also provide medical services. The $\mathrm{KNHI}$ has a compulsory designation system, which means that healthcare providers cannot refuse to provide services to $\mathrm{KNHI}$ subscrib- 
PRECISION AND FUTURE MIEDICINE

National general health screening program in Korea

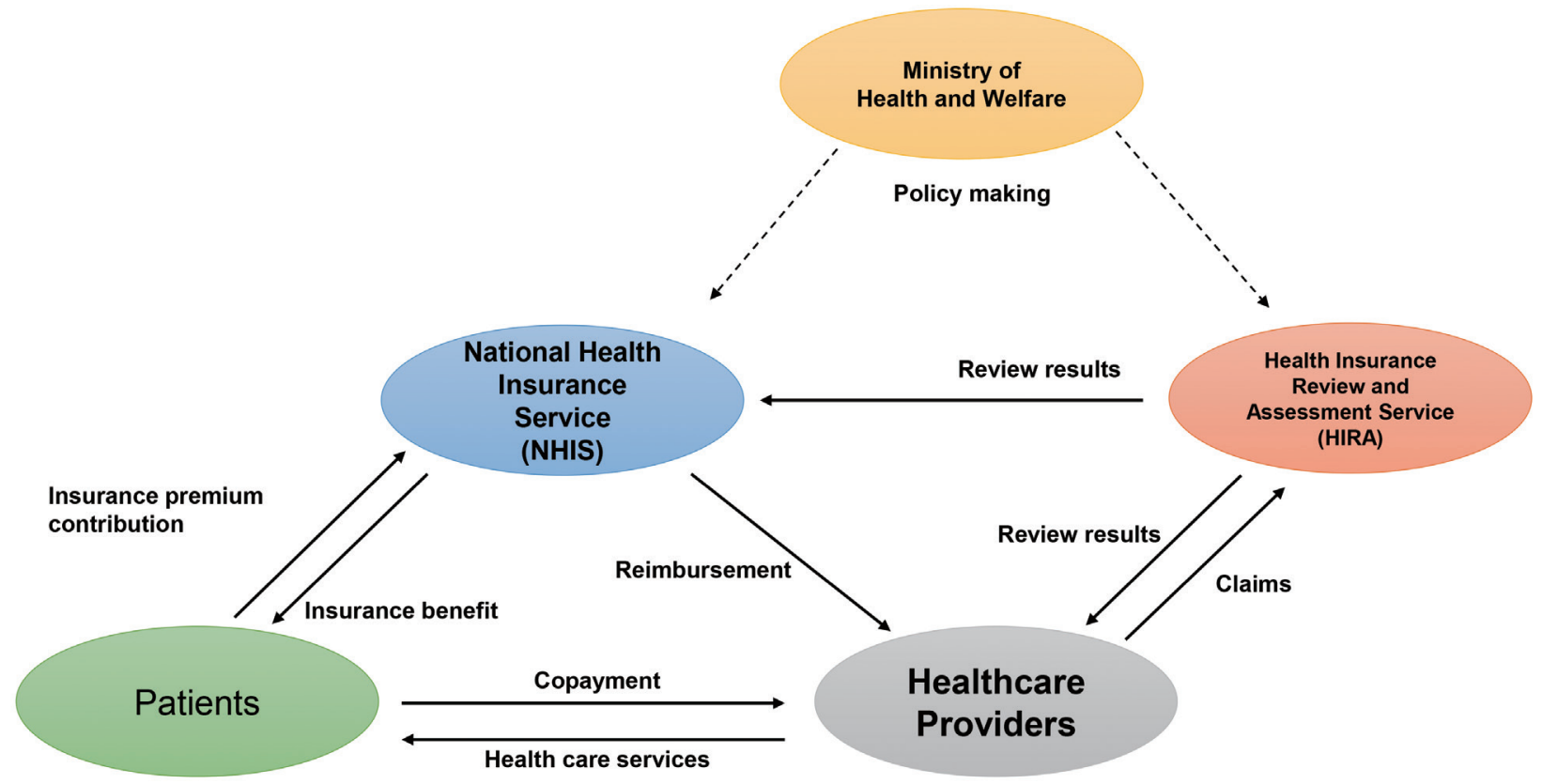

Fig. 2. Health care system in Korea.

ers and MAP beneficiaries (i.e., all the people).

Patients are free to choose their own first-contact provider as well as the referred providers. There is no system of registration to a certain primary care provider, and the role of primary care in gatekeeping is very weak. The patients prefer to receive medical care in tertiary hospitals and are increasingly utilizing it, although the government tries to establish referral and back-referral systems [18,22].

In 2001, the separation of medicine prescriptions and dispensing was enforced to enhance the transparency of the prescription [18]. When a physician prescribes a drug at outpatient care (except for injections), the patients are required to go to the pharmacy and submit the prescription to pick up the drug. Most drugs included in the formulary are covered by the KNHI, with some exceptions.

\section{Payment and reimbursement}

Fee-for-service has been the standard payment model for both outpatient and inpatient care and pharmacy services. However, other payment models have also been tried. For example, case payment based on diagnosis-related groups or per-diem payment has been tried for certain medical conditions. Healthcare providers submit claims to HIRA via the web-based Medical Claim Portal Service. After the claims review is completed, HIRA submits the results to the NHIS, where reimbursement for providers is processed.

All KNHI subscribers are required to pay a certain propor- tion of the medical costs as copayment for the covered services. The copayment of inpatient services is usually $20 \%$. Copayment for outpatient services varies by the level of the healthcare provider and region (urban vs. rural): $60 \%$ for tertiary hospitals, $50 \%$ for general hospitals (45\% in rural areas), $40 \%$ for pharmacy services (35\% in rural areas), and $30 \%$ for small hospitals and clinics. No or minimum copayment is required for MAP beneficiaries.

To prevent catastrophic medical expenditure of the household, the NHIS has been running a copayment reduction program for high cost illness since 2006. Currently (as of 2021), copayment is reduced for: (1) severe illness: cancer (5\%, for 5 years, can be re-registered in case of recurrence or metastatic cancer), cerebral infarction, hemorrhage, and myocardial infarction ( $5 \%$, for acute stage, max 30 days); (2) rare diseases ( $10 \%$, can be extended every 5 years), such as congenital disorders (e.g., hemophilia, glycogen storage disease), rare neurological disorders (e.g., myasthenia gravis, multiple sclerosis, etc.), autoimmune diseases (e.g., Crohn's disease, systemic lupus erythematosus); (3) severe incurable diseases ( $10 \%$ can be extended every 5 years), such as chronic kidney disease (CKD) requiring dialysis, transplantation, schizophrenia, human immunodeficiency virus infection, Parkinson disease, severe dementia, rheumatoid arthritis, and ankylosing spondylitis, etc.; (4) tuberculosis (no copayment). For patients to be eligible for this program, a physician must submit a certification of diagnosis to the NHIS for the patients. Subse- 
quently, a special registration code (e.g., V124 for Parkinson's disease) is endowed in the system by applying copayment reduction. As registration to this program gives much economic benefit, virtually all the patients who meet the criteria are registered.

Another policy to prevent catastrophic medical expenditure is the application of a ceiling on cumulative copayments. Differential ceilings are applied to different income groups; however, the ceiling applies only to insured services.

Notably, full out-of-pocket payments are needed for services and drugs not covered by the KNHI. Most uncovered services are new technologies and medicines with uncertain cost-effectiveness (e.g., robotic surgery or immuno-oncologic drugs, as of 2021) [18], and non-essential services, such as plastic surgery or cosmetic procedures. Currently, healthcare providers do not submit data for uncovered services to the NHIS because they are not reimbursed. The NHIS database does not contain this information.

Copayments for covered services and payments for services that are not covered comprise the out-of-pocket services. The coverage is approximately $60 \%$ to $70 \%$, which means approximately one-third of the total medical cost is borne by out-ofpocket costs. In response, most Koreans (approximately 77\%, according to a recent survey) have supplementary private health insurance [23], although its role has been controversial and questioned $[18,24]$.

\section{Achievement of health outcomes}

Korea has experienced a rapid increase in life expectancy during the last decades and has not reached the top level in the world [25]. It was mainly achieved by reductions in infant mortality and mortality due to infectious and cardiovascular diseases [26]. The authors suggested that the universal health coverage achieved in 1989 might have contributed to this achievement. While the most crucial criteria for good healthcare have not yet been determined, South Korea is rated as having one of the best and most efficient healthcare systems in the world.

\section{GENERAL HEALTH SCREENING PROGRAM IN KOREA}

\section{History of General Health Screening Program in Korea}

Before the enactment of the 'National Health Insurance Act' in 1977 , health screening was mainly performed for industry workers. The first nationwide GHSP began in 1980 with government employees and workers at school (e.g., teachers). It has been imposed on the dependents of corporate employees since 1988. The Ministry of Employment and Labor took charge of the workplace general health examination program from 1977 to 1995, and GHSP could not substitute for this. In 1995, the health screening of corporate employees was transferred to the Ministry of Health and Welfare. In addition, the target population has expanded to self-employees and their dependents since 1995.

The employees and self-employees who pay insurance premiums are eligible for GHSP, regardless of the age every 2 years. The employees involved in manual labor are entitled to receive it every year. For dependents who do not pay insurance premiums, GHSP has been provided to individuals of age $\geq 40$ years every 2 years. While the target disease was not clear during the initial period of GHSP, its primary target was defined as 'cardio and cerebrovascular disease,' and its risk factors, such as hypertension, diabetes mellitus, dyslipidemia, obesity, and smoking became the main target of the program.

In 2007, a special round of NHSP called the "National Screening Program for Transitional Ages (NSPTA)" was launched [27, 28]. The NSPTA targeted two points of age in an individual's lifecycle, namely 40 and 66 years, which are important transition periods to middle age and old age, respectively. To address the problem of increasing suicide and population aging, screening tests for mental health problems (for 40 and 66 years of age), physical function, and osteoporosis (for 66 years) have been introduced [27]. In addition, the follow-up care and education for lifestyle modification was emphasized, taking the example of the Australian 'Lifescript' program (this program was subsequently withdrawn in Australia in 2014 [29]) and mandate the 'secondary screening' process (see the following section) regardless of the result of 'primary screening.' The details of the contents and processes are described elsewhere [27].

With the implementation and expansion of the GHSP for more than 20 years, several issues have been raised [30,31]: (1) lack of strong scientific evidence and rationale for health screening items and interval; (2) unclear goal of the screening program, and no formal evaluation of the effectiveness of the program; (3) changing disease epidemiology and diagnostic modality; (4) assurance of the quality of the diagnostic tests; (5) suboptimal subsequent care after health screening; and (6) reducing the disparity, especially for people with disabilities. In response, the 'Framework act on health examinations (Enactment, March 21, 2008; Enforcement, March 22, 2009; also known as the 'National Health Screening Act')' 
PRECISION AND FUTURE MIEDICINE

National general health screening program in Korea

was formed (All versions of this act are available on the web page of the Korean Law Information Center [32], the last version with partial amendment can be found in Appendix 1).

In 2008 to 2009, there was a major renovation in the content of GHSP. The added screening items included the waist circumference, lipid profile (triglycerides, high-density lipoprotein [HDL] cholesterol, and low-density lipoprotein [LDL] cholesterol), and serum creatinine. The questionnaire on smoking, alcohol consumption, and physical activity underwent major changes in 2009. For example, smoking was changed from a categorical variable (e.g., $<10,10-19,>20$ cigarettes per day) to continuous variable. Alcohol consumption was also changed from a categorical variable (e.g., 1-2, 3-4, 5-7 times per week) to a continuous variable, making it possible to calculate the average amount of alcohol consumption (Appendix 2). In addition, the results of the health risk appraisal for several diseases (e.g., stroke, angina/myocardial infarction, and vascular dementia) were added to the report form (for details of the health risk appraisal, see the following section).

Based on the 'Framework act on health examinations (2008),' a comprehensive plan for national health screening is estab- lished every 5 years: first-term (2011-2015), second-term (2016-2020), and the current third-term plan (2021-2025). As the NHSP comprises numerous screening programs, several ministries, and government organizations (Ministry of Health and Welfare, Ministry of Education, Ministry of Employment and Labor, Ministry of Gender Equality and Family, Center for Disease Control and Prevention, and National Cancer Center) participate in this planning. The GHSP is controlled by the Ministry of Health and Welfare.

Since 2018, NSPTA was stopped, and the items from NSPTA were integrated into the GHSP with the expansion of target ages. Since 2019, individuals aged 20 to 39 years, who are not employees have been included in the GHSP, resulting in adults aged 20 years and over eligible for GHSP [33]. A brief history of the NHSP and GHSP is summarized in Table 1.

\section{Target diseases and items of General Health Screening Program}

The health screening items and their target disease, screening age, interval program, and items are displayed in Table 2. There are items that have been included from the start of the program (for GHSP, since the 1980 to 1990s), when the health ex-

Table 1. Brief history of National Health Screening Program for adult population in Korea

\begin{tabular}{|c|c|}
\hline Year & History \\
\hline 1950 & Mass examination for tuberculosis and parasite disease \\
\hline 1953 & Mandatory imposition of periodic health checkup for workplace of 16 people or more (labor standard law) \\
\hline 1977 & Ministry of Employment and Labor took charge of workplace general health examination for corporate employee (1977-1995) \\
\hline 1980 & Imposition of general health screening for government employee and workers at school (e.g., teacher) \\
\hline 1988 & Imposition of general health screening for dependents of corporate employee \\
\hline 1995 & Transfer of health screening of corporate employee to Ministry of Health and Welfare \\
\hline 1995 & Imposition of general health screening to self-employees (regional policy holders) \\
\hline 1999 & Imposition of National Cancer Screening Program for medical aid: stomach, colorectal, liver, breast, and cervix cancer \\
\hline 2000 & Healthcare financing reform merging all medical insurance societies into the single National Health Insurance Service (NHIS) \\
\hline 2005 & Imposition of National Cancer Screening Program for NHI subscriber (lower income 50\%) \\
\hline 2007 & Imposition of special round of health screening called 'National Screening Program for Transitional Ages (NSPTA)' for age 40 and 66 \\
\hline 2008 & Framework act on health examinations (Enactment, March 21, 2008; Enforcement, March 22, 2009) \\
\hline 2009 & Major renovation of health screening items, questionnaire, and adoption of health risk appraisal \\
\hline 2010 & First-term (2011-2015) comprehensive plan for national health screening \\
\hline 2012 & Imposition of general health screening for Medical Aid Recipient \\
\hline 2016 & Second-term (2016-2020) comprehensive plan for national health screening \\
\hline 2018 & Integration of NSPTA to General Health Screening Program \\
\hline 2019 & Expansion of general health screening to younger population (20-39 years of age) \\
\hline 2019 & Imposition of national lung cancer screening program \\
\hline 2021 & Third-term (2021-2025) comprehensive plan for national health screening \\
\hline
\end{tabular}


PRECISION AND FUTURE MEDICINE

Dong Wook Shin, et al.

Table 2. Health screening items and target diseases for national General Health Screening Program in Korea

\begin{tabular}{|c|c|c|c|c|c|}
\hline Categories & Health screening items & Target disease & As of 2002 & As of 2009 & As of 2021 \\
\hline & Blood pressure & Hypertension & 2 years & 2 years & 2 years \\
\hline & Visual acuity & Visual impairment & 2 years & 2 years & 2 years \\
\hline \multirow[t]{6}{*}{ Questionnaire } & Past medical history & General health risk & 2 years & 2 years & 2 years \\
\hline & Smoking & Health behavior & 2 years & 2 years & 2 years \\
\hline & Alcohol consumption & Health behavior & 2 years & 2 years & 2 years \\
\hline & Physical activity & Health behavior & 2 years & 2 years & 2 years \\
\hline & Urinary dysfunction & $\begin{array}{l}\text { Urinary } \\
\text { incontinence }\end{array}$ & 2 years & 66 years of age & $\begin{array}{c}66,70, \text { and } 80 \text { years } \\
\text { of age }\end{array}$ \\
\hline & Previous fall & Fall & NA & 66 years of age & $\begin{array}{c}66,70 \text {, and } 80 \text { years } \\
\text { of age }\end{array}$ \\
\hline \multirow[t]{5}{*}{ Blood test } & Hemoglobin & Anemia & 2 years & 2 years & 2 years \\
\hline & Fasting blood glucose & Diabetes mellitus & 2 years & 2 years & 2 years \\
\hline & $\begin{array}{l}\text { Blood lipid level: } \\
\text { Total cholesterol } \\
\text { Triglyceride } \\
\text { HDL cholesterol } \\
\text { LDL cholesterol }{ }^{\text {a) }}\end{array}$ & Dyslipidemia & $\begin{array}{l}2 \text { years (total choles- } \\
\text { terol only) }\end{array}$ & 2 years & $\begin{array}{l}\text { Male: from } 24 \text { years of } \\
\text { age, every } 4 \text { years } \\
\text { Female: from } 40 \text { years } \\
\text { of ag, every } 2 \text { years }\end{array}$ \\
\hline & Hepatitis B antigen/antibody & Chronic hepatitis B & & 40 years of age & \\
\hline & $\begin{array}{l}\text { Creatinine, estimated } \\
\text { glomerular filtration rate }\end{array}$ & Renal disease & NA & 2 years & 2 years \\
\hline Urine test & $\begin{array}{l}\text { Dipstick test (urinary } \\
\text { protein) }\end{array}$ & Renal disease & 2 years & 2 years & 2 years \\
\hline \multirow[t]{2}{*}{ Imaging test } & Chest X-ray & $\begin{array}{l}\text { Tuberculosis, chest } \\
\text { disease }\end{array}$ & 2 years & 2 years & 2 years \\
\hline & $\begin{array}{l}\text { DEXA bone densitometry, } \\
\text { peripheral bone (calcaneous) } \\
\text { ultrasound/quantitative CT, } \\
\text { etc. }\end{array}$ & Osteoporosis & NA & $\begin{array}{c}\text { Female, } 66 \text { years } \\
\text { of age }\end{array}$ & $\begin{array}{c}\text { Female, } 54 \text { and } 66 \\
\text { years of age }\end{array}$ \\
\hline $\begin{array}{l}\text { Cognitive function } \\
\text { test }\end{array}$ & $\begin{array}{l}\text { Korean Dementia Screening } \\
\text { Questionnaire-C }\end{array}$ & Dementia & NA & 66 years of age & $\begin{array}{c}\text { From } 66 \text { years of age, } \\
\text { every } 2 \text { years }\end{array}$ \\
\hline
\end{tabular}


PRECISION AND FUTURE MIEDICINE

National general health screening program in Korea

Table 2. Continued

\begin{tabular}{|c|c|c|c|c|c|}
\hline Categories & Health screening items & Target disease & As of 2002 & As of 2009 & As of 2021 \\
\hline \multirow[t]{2}{*}{$\begin{array}{l}\text { Physical function } \\
\text { test }\end{array}$} & Timed Up and Go test & Fall & NA & 66 years of age & $\begin{array}{c}66,70 \text {, and } 80 \text { years } \\
\text { of age }\end{array}$ \\
\hline & $\begin{array}{l}\text { Balance test (unipedal stance, } \\
\text { etc.) }\end{array}$ & Fall & NA & 66 years of age & $\begin{array}{c}66,70 \text {, and } 80 \text { years } \\
\text { of age }\end{array}$ \\
\hline Mental health test & $\begin{array}{l}\text { Center for epidemiology- } \\
\text { depression scale (CES-D) } \\
\text { Geriatric depression scale } \\
\text { (GDS) } \\
\text { Patient Health } \\
\text { Questionnaire- 9 (PHQ 9) }\end{array}$ & Depression & NA & $\begin{array}{l}40 \text { years of age } \\
\text { (CES-D) } \\
66 \text { years of age } \\
\text { (GDS) }\end{array}$ & $\begin{array}{c}\text { 20, 30, 40, 50, 60, } 70 \\
\text { years of age (PHQ9): } \\
\text { once in a 10-year } \\
\text { period }\end{array}$ \\
\hline
\end{tabular}

2 years: 1 year for workers in manual labor. Questionnaire on smoking, alcohol consumption, and physical activity underwent major change in 2009. Screening test for Medical Aid Program recipeinet is slightly different in their age or interval.

NA, not available; HDL, high-density lipoprotein; LDL, low-density lipoprotein; DEXA, dual-energy X-ray absorptiometry; CT, computed tomography.

a) LDL: calculated by Friedewald formula, direct measurement is performed when triglyceride $>400 \mathrm{mg} / \mathrm{dL}$.

amination was mainly targeted for workplace employees. At that time, the concept of evidence-based medicine was not common. It has continuously changed, and major changes were made in 1995, 2009, and 2018. We introduced items for 2002 (currently GHSP data available from this year), 2009 (major change in screening items), and 2021 (current practice).

\section{Cardio-cerebrovascular disease and its risk factors}

The main target diseases of GHSP are cardiovascular and cerebrovascular diseases [34]. Therefore, screening for hypertension, diabetes mellitus, dyslipidemia, and obesity are the core items, as well as a health behavior assessment for lifestyle counseling. The waist circumference, and triglyceride, HDL, and LDL cholesterol levels were added in 2009. Hemoglobin $\mathrm{A} 1 \mathrm{C}$ is currently not included in this program.

\section{Other target diseases and additional items}

In 2008, serum creatinine was added (while it was included in the GHSP during 1991-1996). Because CKD has a long asymptomatic phase and awareness of this disease is very low, it is potentially a good screening target, as advocated by the nephrologist society [35]. However, the US Preventive Service Task Force (USPSTF) concluded that the current evidence is insufficient [36]; additionally, American college physicians recommend against it [37].

The urine dipstick test has been performed since 1988. At the initial stage, it also included urine glucose, urine occult blood test, and urinary $\mathrm{pH}$; however, it was excluded from 2009. Currently, although there is insufficient evidence [36], testing for urine protein is performed in the GHSP.
Hemoglobin has long been a part of the GHSP since its initial period, probably because nutritional deficiency and anemia were more common at that time. Currently, routine screening for iron deficiency anemia is not recommended even for pregnant women [38]; however, it is still included in the program. It is also suggested that screening for anemia and treating iron deficiency could be beneficial [39].

Rationale for routine liver function tests in asymptomatic individuals is also lacking [40]; however, this might be due to the high prevalence of hepatitis B in the past. Screening for hepatitis B antigen/antibody was performed at the initial stage of GHSP (1995). Prevalence of hepatitis B has dramatically decreased due to the hepatitis $B$ vaccination after birth since the 1980s [41]. Screening for hepatitis B antigen/antibody was included in the NSPTA at age 40 in 2007. Currently, abnormal liver function test results are mostly due to non-alcoholic fatty liver disease [42,43].

Korea has long been endemic for tuberculosis: the prevalence of latent or active tuberculosis infection for individuals of age $<30$ years was $47 \%$ in the 1970 s and remained over $15 \%$ even in 1995 . Therefore, examinations by chest radiography have been included since the 1950s [44]. Currently, if tuberculosis is suspected, confirmatory testing and treatment are provided without copayment (for copayment reduction program, please see above section). The physician is required to report all suspected or confirmed cases to the public health centers in the region within 24 hours through a web-based notification system. There are also other special programs for tuberculosis screening, such as mobile van screening for vulnerable older adults, because their partici- 
pation in the GHSP is low. The current USPSTF guidelines recommend screening for latent tuberculosis using the Mantoux test or interferon-gamma release assays (IGRA) [8]. However, as Korean individuals receive Bacille Calmette-Guérin vaccination after birth, testing with IGRA may be preferable. Screening for latent tuberculosis is performed mainly for healthcare professionals or school employees outside of the GHSP.

Visual acuity and hearing tests were performed without a specific target disease. The visual acuity measurement procedure at the GHSP follows the KSP ISO 8596, which is a Korean modification of the international standard [45]. The measurement is performed using a standard visual acuity chart placed more than $4 \mathrm{~m}$ from the individual being tested under bright room light (> 200 lux). Spectacle-corrected visual acuity is recorded for participants using glasses. A hearing assessment is conducted by pure tone audiometry at a single frequency of $1,000 \mathrm{~Hz}$, and formal audiometric testing at various frequencies is not available [46]. The result is dichotomously recorded as 'pass' ( $<40 \mathrm{~dB}$ hearing level) or 'fail' (criterion for referral for further workup). There are suggestions that more sophisticated auditory examinations, such as highfrequency hearing loss $(3,000 \mathrm{~Hz})$, should be considered to achieve early hearing rehabilitation and better quality of life $[46,47]$. Although the current evidence is insufficient to recommend screening for visual acuity and hearing loss in general older adults $[48,49]$, testing for visual acuity and hearing has a potential role in identifying older adults with sensory problems and communication difficulties.

\section{Mental health}

With increasing suicide rates, which is highest in the world $[50,51]$, emphasis has been placed on mental health. In the NSPTA, which was introduced in 2007, screening for depression was included for patients aged 40 and 66 years [27]. For age 40, four selected questions from the Center for Epidemiologic Studies Depression (CES-D) scale was used as a primary screening tool; additionally, if participants answered 'yes' to any item, the full 20 items of the CES-D were tested as a secondary screening test [52]. For age 66, three selected questions from the Geriatric Depression Scale (GDS) were included in the questionnaires [53]. As earlier, any positive answer to any of the items will make the participants eligible to the complete 15 items of the GDS.

Since 2018, screening for depression has expanded to the age of 40 and above $(40,50,60$, and 70$)$ every 10 years. It was expanded to 20 years and above in 2019, and as of 2021, pa- tients undergo screening once in a 10-year period (recommended for the ages $20,30,40,50,60$, and 70 , but if missed, they can undergo the test in the next round of screening). The screening tool was changed to the Patient Health Questionnaire-9 (PHQ-9), which was initially developed for primary care patients [54] and proven to be valid for the general population [55], and recommended by the current guidelines [5]. Validity has been demonstrated in the Korean elderly population [56], and normative data in the general population have been published [54]. It has nine items, with each item scored between 0 and 3 . A total score of 5 or more is regarded as having depression (5-9, mild; 10-19, moderate; and 20-28, severe). A primary physician is required to refer the participants to a psychiatrist if the PHQ-9 score is 10 or more (Appendix 3).

\section{Diseases and cognitive/physical functions of older people} With the rapid aging of the population and changes in the disease burden, items for health screening have been expanded to meet the needs of the elderly population. Screening for osteoporosis and cognitive dysfunction was added to the NSPTA program in 2007 and expanded with the integration of the GHSP and NSPTA in 2018.

In 2007, screening for osteoporosis was included in the NSPTA for women aged 66 years. Currently, the methods included dual-energy $X$-ray absorptiometry (DEXA), peripheral DEXA, quantitative computed tomography (QCT), peripheral $\mathrm{QCT}$, and quantitative ultrasound. The most widely used method is DEXA, and the use of other methods has decreased owing to its accuracy. For DEXA, measurement is primarily performed in the vertebra; however, if it is impossible, measurement at the hip is possible. Since 2018, screening for osteoporosis has been provided to women aged 54 years.

Screening for cognitive dysfunction testing was also introduced in the 2007 NSPTA for individuals of 66 years of age. Since 2009, people aged 70 and 74 years have become eligible to undergo screening for cognitive dysfunction as part of the GHSP. With the integration of NSPTA to the GHSP, screening for cognitive dysfunction is applied to every individual aged 66 years and above every 2 years [21]. The initial screening was performed using the Korean Dementia Screening Questionnaire-Prescreening (KDSQ-P), which is composed of five items, of which four items evaluate the memory function and the remaining item assesses the abilities associated with daily living [57]. It is primarily performed by accompanying family members; however, if the patient came for health screening without one, he or she could fill the questionnaire 
PRECISION AND FUTURE MIEDICINE

National general health screening program in Korea

by himself/herself. Each item is scored 0 -2, with a total score in the range of $0-10$. A high score indicates poor cognitive function, and patients with a cut-off score $\geq 4$ undergo further testing with the Korean Dementia Screening Questionnaire-Cognition (KDSQ-C) (Appendix 4). The KDSQ-C comprises 15 items, and each item is scored $0-2$. It is also performed by accompanying family members; however, it can be done by the participants themselves. It has a negative correlation with the Korean Mini-Mental State Examination (KMMSE, $\gamma=-0.65$ ), and has a sensitivity and specificity of $79 \%$ and $80 \%$ for screening dementia at a cut-off score of 6 [58]. KDSQ-P has a high correlation with KDSQ $(\gamma=0.741)$. The detailed items of the KDSQ-P and KDSQ-C (in Korean) can be found elsewhere [57].

Physical function is important for the health of older individuals. Screening for fall risk was introduced in the 2007 NSPTA for the age of 66 years and included (1) a Timed Up and Go (TUG) test; (2) a unipedal stance test (UPS); and (3) a question on previous falls. The TUG is a reliable and valid test for quantifying the functional mobility in older adults and assessing the fall risk in community settings [59]. The TUG time was measured as the time required to rise from a straight backed chair without arm rest, walk at a comfortable pace for $3 \mathrm{~m}$, turn around, walk back to the chair, and sit down again [59]. The cut-off point of the TUG test to identify individuals at high-risk of falls varies depending on the study population (from 10 to 33 seconds) [60]. For example, in a study of community-dwelling British elderly, a TUG time $\geq 12.6$ seconds showed a significant association with future falls (adjusted odds ratio,3.94; 95\% confidence interval, 1.69 to 9.21), with $30 \%$ sensitivity and $89 \%$ specificity [51]. In the Korean NSPTA, the TUG results for 66-year-old individuals are classified as normal if $<10$ seconds, borderline if between 10 and 20 seconds, or abnormal if $\geq 20$ seconds based on an expert consensus. In a Korean National Health Information Database (NHID) study, slow TUG test results, indicating frailty, were found to be well associated with a high-risk of osteoporotic fracture [61], dementia [62], Parkinson's [63], and cardiovascular disease [64]. The UPS is convenient to be performed in primary care, and UPS alone was suggested to replace the combination of UPS and TUG [65]. The question on previous falls is asked for the last 6 months. These tests are now performed for individuals at 66,70 , and 80 years of age.

In addition, the activities of daily living were evaluated with a 6-item questionnaire that combines four items from the Korean Activity of Daily Living (K-ADL) and two items from the Korean Instrumental Activity of Daily Living (K-IADL) scales [66]. Screening for urinary dysfunction and checking for recent influenza and pneumococcal vaccinations were also performed (Appendix 5).

\section{Provision and reimbursement NHSP providers}

NHSP providers are widely distributed throughout Korea. To be the providers of NHSP, medical institutions should apply for designation to NHIS, review whether they meet the criteria of the NHIS and local government, and be designated by the local government. Approximately $41.1 \%$ of the medical institutions in Korea are participating in this program. At the institutional level, $97.2 \%$ of general hospitals, $33.9 \%$ of hospitals, $27.4 \%$ of clinics, $10.0 \%$ of public health centers, $82.0 \%$ of dental hospitals, and $68.3 \%$ of dental clinics are participating [21].

Based on the 'Framework act on health examinations,' NHSP providers are evaluated to assure the quality of screening programs and to promote quality improvement. The evaluation program for National Cancer Screening Program (NCSP) started in 2008, and that for the GHSP started in 2010 [67]. The items include environment, human resources, and their education, facility, procedure, quality control, etc. The results of this evaluation are publicly disclosed on the NHIS website.

\section{Reimbursement}

The NHSP cost is reimbursed by the NHIS. The basic reimbursement rate is 456,770 Korean won (equivalent to approximately 40 US dollars [USD], as of 2021, 1 USD is approximately 1,150 Korean won [KRW]) for physician consultation and administration, anthropometric measurements, blood and urine tests, and chest radiography. Additional items are reimbursed separately: for example, DEXA (36,350 KRW), screening for cognitive dysfunction (4,330 KRW), screening for depression (4,290 KRW), and physical function test (2,400 KRW) [68].

\section{Operation process}

An illustration of the overall process of the GHSP is displayed in Fig. 3. The GHSP is provided biennially; however, employees involved in manual labor can get it annually.

\section{Identification and invitation of eligible subjects}

The NHIS identifies the subjects eligible for the GHSP and sends an invitation letter. The NHIS encourages participation in the NHSP through public campaigns, such as television and media advertisements or outdoor advertising. The participants are free to choose any certified medical institutions, 


\section{PRECISION AND FUTURE MIEDICINE}

Dong Wook Shin, et al.

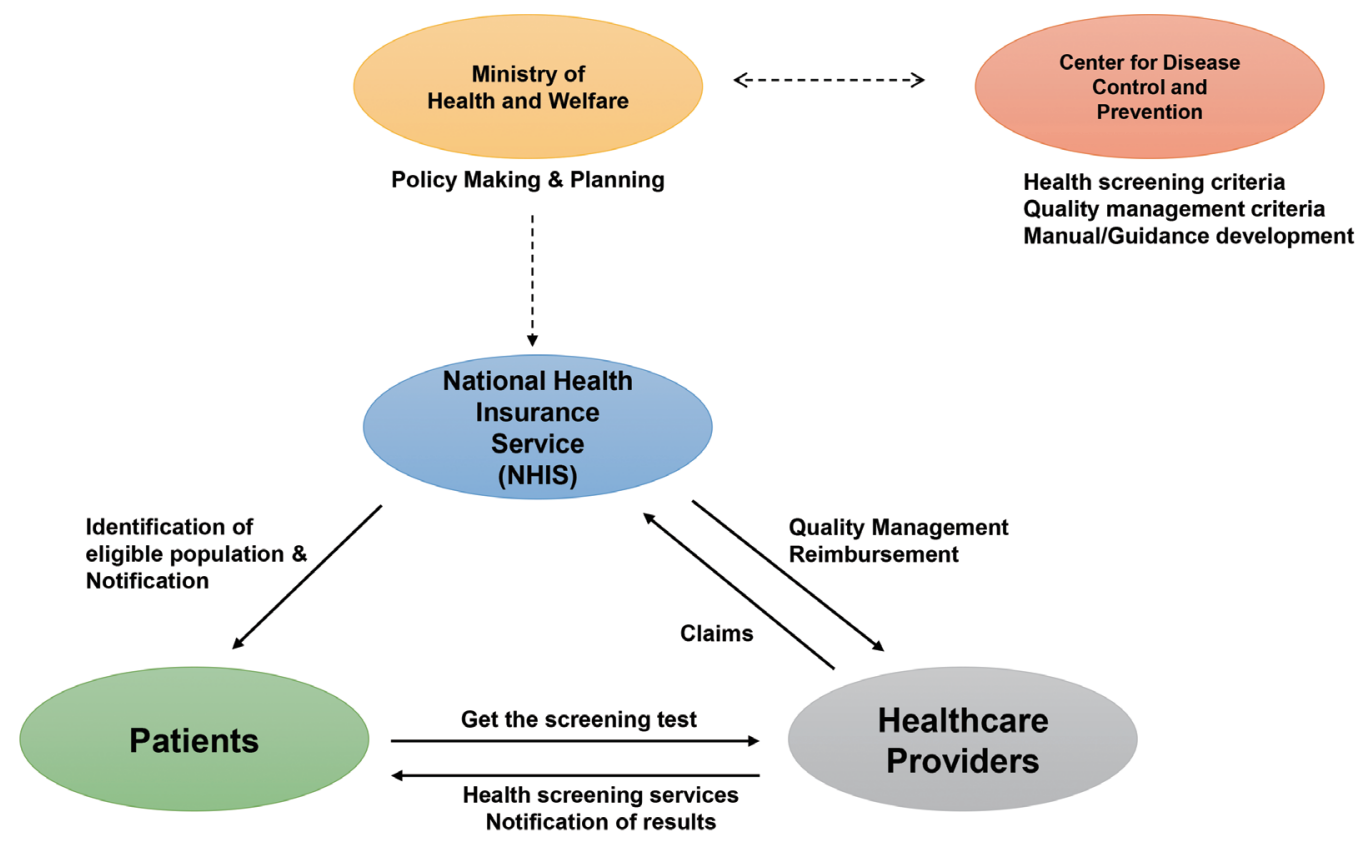

Fig. 3. Operation system for General Health Screening Program in Korea.

including private clinics, hospitals, and public health centers for their screening examinations.

By the 'Occupational Safety and Health Act (2019),' a business owner should ensure that their employees get 'worker's general health examinations (WGHE) to protect the workers health [17]. The intervals are every year for manual laborers and 2 years for others. This WGHE can be substituted with the GHSP covered by the National Health Insurance. Therefore, for workplace employees, the list of eligible employees is sent from the NHIS to the business owner so that the corporation can arrange group participation in GHSP. There is a financial penalty to the business owner if their employees do not participate in the GHSP. Therefore, the participation rate among workplace employees is very high $(83 \%$ overall and $91 \%$ for non-office workers) [17].

\section{Screening procedure}

The participants are instructed to fast overnight from 9:00 PM before the health screening date, and to refrain from drinking alcohol or having night shifts.

\section{1) Questionnaire}

Before the screening, the participants are asked to fill out a questionnaire regarding their past medical history and health behaviors, such as cigarette smoking, alcohol consumption, and exercise (Appendix 2, retrieved from the NHIS website). It is usually self-administered; however, assistance is provided when the participants have problems with visual acuity or cognitive function. Recently, questionnaires were completed through the NHIS website (www.nhis.or.kr) or mobile application (The National Health Insurance) before visiting the medical institution for GHSP. Missing data often occurs with these questionnaire items, but usually is not problematic, and is reported to be approximately $5 \%$ for most studies (varies by the eligibility criteria).

\section{2) Anthropometric measurement}

There is a standard measurement protocol for GHSP, and institutions are periodically evaluated to determine whether they follow the protocol. For example, all the participants are recommended to avoid smoking, alcohol, or caffeine intake, and the need to rest for at least 5 minutes in a seated position prior to the first measurement. The blood pressure (BP) should be measured in a quiet environment by auscultation or by using an oscilloscopic automatic sphygmomanometer. The devices should be calibrated daily. A cuff with an appropriately sized bladder should be used (the standard cuff size for adults is $12 \mathrm{~cm}$ wide and $26 \mathrm{~cm}$ long). A study found that most GHSP institutions perform BP measurement according to an established protocol, although there are some discrepancies and room for improvement [69]. The waist circumference (WC) is measured at the midpoint between the inferior border of the lower rib and the iliac crest on the mid-axillary line after exhalation. 
PRECISION AND FUTURE MIEDICINE

National general health screening program in Korea

\section{3) Laboratory test}

Blood samples are taken by qualified personnel and handled and stored appropriately to prevent hemolysis or clotting. The participants are instructed to collect at least $10 \mathrm{~mL}$ of mid-stream urine after at least 4 hours from the last voiding. Each institution should have internal and external quality control procedures, as overseen by the Korean Association of Laboratory Quality Control. Chest radiography should be performed by a radiologist and read by a board-certified radiologist [70].

\section{Reporting}

The results of the health screening are provided as a report, containing the following: (1) health checkup general comments, (2) detailed examination results, (3) cardiovascular disease risk assessment (health risk appraisal), and (4) assessment results of life habits. The report form has been continuously changed with the change of health screening items: the current English version is provided in Appendix 6; one sample of the previous versions can be found elsewhere [71]; in the general comments section, the participants are classified as (1) no disease (normal A), (2) at boundary status (normal B, e.g., prehypertension or prediabetes), and (3) suspected disease (e.g., hypertension or diabetes mellitus is suspected). The detailed examination results are provided in reference values.

Cardiovascular disease risk assessment is designed to help better understand their risk as absolute risk (i.e., 10 year risk of developing cardiovascular disease), relative risk (i.e., 0.00 times the risk compared to the average for the participants of the same age and sex), and cardiovascular age (equivalent risk of those with $\mathrm{OO}$ years of age and same sex), and how much their risk can be decreased by adopting better health behaviors and risk factor management. The 'Health traffic light' color is also used to visualize the risk: low risk (green), medium risk (yellow), and high-risk (red). This is based on the health risk appraisal methods, which have been adopted by the GHSP since the early 2000s. The first health risk appraisal (HRA) model was developed to predict the overall mortality [72,73], and subsequently included risk prediction for cancer and vascular dementia in the mean time. However, since 2018 , it has focused on cardiovascular risk assessment $[74,75]$.

The details of lifestyle prescription follow, including the recommendations for smoking cessation medication (nicotine replacement therapy, bupropion, and varenicline), referral to a smoking cessation clinic or alcohol rehabilitation center, and recommendations for healthier diet and exercise. This screening report is sent to the participant by regular mail usually within 15 days of the screening date.

\section{Confirmatory tests and subsequent care}

Those individuals with abnormal results at the GHSP (e.g., high fasting blood sugar or BP level outside the range) are instructed to undergo confirmatory diagnostic tests. By 2017, this confirmation process was called 'secondary examination,' and participants were provided a confirmatory test without cost from the medical institution at which the participants took GHSP. However, several individuals chose to go directly to medical care outside the GHSP when they were notified of the abnormal results, as they were free to visit any medical institution as convenient.

In 2018, 'secondary examination' was abolished, and participants who are suspected for a particular disease can get a confirmatory test from any medical institution, without the need to get it at a medical institution at which the participants took GHSP. Copayment for medical visits and confirmatory tests is waived. If a diagnosis is confirmed, counseling with a physician and subsequent medical treatment should be followed.

\section{KOREAN NATIONAL HEALTH INFORMATION DATABASE AND USE OF GHSP DATA FOR RESEARCH}

\section{Korean National Health Information Database}

As described above, as a single insurer in Korea, the NHIS manages all administrative processes and reimburses the medical providers and pharmacies based on their claims for the provision of medical and pharmacy services. The NHIS also provides NHSP, including GHSP and NCSP, for all eligible Korean individuals. The administrative process of MAP beneficiaries is also entrusted to the NHIS by the Ministry of Health and Welfare. Therefore, the Korean NHIS database contains the health information of all Korean people (approximately 52 million), including eligibility (age, sex, place of residence, insurance premium level as a proxy for income level, disability status -15 legally defined types and severity $[76,77]$, etc.), medical utilization (diagnosis code [defined by the Korean Standard Classification of Diseases 7th revision, primarily the same as the International Classification of Diseases 10th Revision] with a few changes specific to the Korean situation, diagnostic and therapeutic procedures, prescriptions, medical expenses), and results of the health examinations. 
In 2012, the NHIS established the NHID, which incorporates five databases of NHIS: (1) eligibility database; (2) national health screening database; (3) healthcare utilization database; (4) long-term care insurance database (included since 2014); and (5) healthcare provider database. As Korea has a registration system in which all citizens have a unique 13 digit identification code, data linkage is theoretically easy. The mortality data (date of death) are routinely linked from the Statistics of Korea for eligibility management; however, the cause of death data are not routinely linked. Data from the Korean Cancer Registry [78] have been rarely performed with special approval for policy research purposes of special projects, and are not officially available to researchers as of 2021. Korea has a disability registration system, containing the details of disability causes, etc.; however, this data is also generally not linked currently. Nevertheless, the disability types and severity information were included in the NHID.

This NHID is not primarily used for research purposes. However, the NHIS operates the National Health Insurance Sharing Service (NHISS) to provide support for policy and academic research using the NHIS information. The data are provided in two ways. The first is a sample research database, which is a pre-established database, and includes five DBs currently: (1) a sample cohort database consisting of $2 \%$ (about 1 million people) of the Korean population in 2002, including claims, health screening, and mortality data until 2013 [79]; (2) medical checkup (or national health screening) database: $10 \%$ of 2002 to 2003 GHSP participants aged 40 to 79 (about 0.51 million) followed up to 2013 [80]; (3) elderly (senior) cohort: $10 \%$ (about 0.56 million people) of the Korean population aged $\geq 60$ years as of 2002 followed up to 2015, and included additional information on long-term care insurance [81]; (4) the working women cohort; and (5) infant medical checkup cohort. The cause of death data have been linked to the Statistics of Korea for these sample databases. The accuracy of the cause of death in Korea is reported to be approximately $92 \%[80,82]$. This sample database is relatively accessible to researchers. Recently, family history research has also become possible through the establishment of a family tree database (although not available through the NHISS website, as of September 2021) [83]. The second is a customized database, which is designed to conform to the request of researchers. The cause of death data are not readily available for a customized database, and linkage to mortality data from Statistics Korea requires additional administrative processes.

The NHID data are provided through the NHISS once the research proposal is officially reviewed and approved. The approval or exemption of approval from the Institutional Review Board is a prerequisite for the proposal application. Informed consent was waived as NHID involved only anonymized and de-identified information. Raw data cannot be exported from the NHIS, and can be analyzed through remote connection through a virtual research room (sample data) or at the data analysis room in the NHIS (customized database). Details of the structure, contents, and list of variables in NHID can be found elsewhere $[19,84]$. Further, details of the data request process are detailed in the NHISS website (https://nhiss.nhis.or.kr/bd/ab/bdaba000eng.do).

Moreover, HIRA provides a sample database: the national patient sample (HIRA-NPS, $3 \%$ of the patient population), the national inpatient sample (HIRA-NIS, 13\%), aged population sample (HIRA-APS, 20\%), and the pediatric patient sample (HIRA-PPS, 10\%) [85,86]. However, the HIRA database is limited as it does not have eligibility information (e.g., insurance premium level, area of residence, etc.) and the health screening data.

\section{Research using GHSP information}

NHID information has been used for various epidemiologic and policy research, including the evaluation of prevalence or incidence $[87,88]$, identification of disease risk factors [8994], description of treatment pattern or disease control status [95], and pharmacoepidemiology [96,97]. Several fact sheets were also made with GHSP data from the NHID [98,99]. With the emerging importance of real-world evidence [100], its use has been increasing.

Currently, several studies using the GHSP data take 2009 and 2010 as the baseline, as there were major changes in the health screening items and questionnaires in 2009, as described above [71]. Among the eligible individuals, the screening participation rates were approximately $66 \%$ in 2009 and $68 \%$ in 2010 [71].

Using the health screening data in NHID has several strengths. (1) Large sample size, representativeness for the nation, and low attrition rate make the research very efficient; (2) It has large data on the general younger population, which are different from the claims data from the US Medicare (older population) and Medicaid program (low-income population); (3) GHSP information is available for health behavior, anthropometric measurements, physical function test, and laboratory results, which are not included in other claims databases, such as one in Taiwan. In Korea, the test results from routine clinical care are not submitted to NHIS for reimbursement purpose. For 
PRECISION AND FUTURE MIEDICINE

National general health screening program in Korea

example, when a patient is diagnosed with cancer and receives routine preoperative tests; for example, the test results are not available in the KNHI database. Therefore, some research linked GHSP results within 1 to 2 years prior to the cancer diagnosis are required to adjust for health screening behaviors and other potential confounders [101,102].

However, there are some limitations to this study. First, the NHID database was established primarily for the administration of eligibility and reimbursement management and is not optimal for research purposes. Caution is needed for the operational definition of diseases for the study population, covariates, or outcomes, as disease can be over- or underdiagnosed in practice. For example, asymptomatic diseases are often underdiagnosed, while some diseases can be over-coded for reimbursement purposes. Validation compared to the hospital data has been infrequently performed $[103,104]$. To reduce inaccuracy, various methods can be used to improve the operational definition, such as limiting the diagnosis registered in hospital admission, requiring repeated outpatient visits, the combined use of GHSP results, combination with prescription records (some examples of cardiovascular disease research are found elsewhere [100]), or the use of a special registration code for copayment reduction (e.g., for cancer [89-91,96], tuberculosis [105], or rare/intractable disease $[93,94]$, as described above). Due to the official process for the copayment reduction program as described above, data accuracy using this registration program code should be reasonably high; for example, for hypertrophic cardiomyopathy, sensitivity, specificity, and accuracy were $91.5 \%, 100 \%$, and $92.6 \%$, respectively [104]. Second, the health screening participants are not representative of the entire population, because participation itself is not mandatory. Screened participants are more likely to be employees, have higher income, better health behavior, lower mortality, and lower total medical expenditure $[21,34]$. Lastly, the screening interval between repeated GHSP screening is not uniform, because patients can undergo screening at any time of the year when they are eligible. For example, among those who participated in health screening in 2009 to 2010 (regarded as baseline in a study by Kim et al. [71]), approximately $77 \%$ participated in round 2 (after 1 or 2 years), and 53\% participated in round 3 (after 3 or 4 years) [71]. This is different from the prospective cohort study, in which the examination intervals are strictly controlled. However, data from the repeated examination of GHSP can be a good source for research on changes in the health status. Several studies take a 2-year interval to investigate the association between change/persistency in health behavior (for example, smoking. alcohol, physical activity) or test results (obesity, lipid profiles), and health outcomes (cardiovascular disease) [106-108]. Other studies have investigated the association between variability in cardiometabolic parameters and health outcomes [90,92,109].

\section{EFFECT OF GSHP ON HEALTH AND BEHAVIORAL OUTCOMES}

Randomized controlled trials (RCTs) are the gold standard for assessing health screening effectiveness. Previous large-scale RCTs and systematic reviews have generally found no benefit of general health screening and lifestyle interventions [110, 111]; however, as GHSP has long been the national program, it is practically impossible to design and conduct RCTs in the current system; additionally, evidence for its effectiveness should come out from real-world data.

The recent third-term (2021 to 2025) comprehensive NHSP plan in Korea takes the following indirect evidence of increasing disease control rates and decreasing population mortality to back up their policy decisions [21]. According to the Korean National Health and Nutrition Examination Survey (KNHANES) data between the time periods of 2010-2012 and 2016-2018, the treatment and control rates for hypertension increased from $60.7 \%$ to $65.4 \%$ and $69.3 \%$ to $73.1 \%$, respectively. Additionally, those figures for diabetes mellitus increased from $63.9 \%$ to $66.2 \%$ and $26.0 \%$ to $25.8 \%$, respectively [21]. According to the national mortality statistics, mortality from diabetes mellitus, ischemic heart disease, and cerebrovascular disease also decreased from 21.5 to $15.8,27.1$ to 26.7 , and 50.7 to 42.7 , respectively, per 100,000 person-years between the time-period of 2011 to 2019 [21].

Additional direct evidence can be found by comparing the screening participants and non-participants. Lee et al. [34] found that the screened participants showed lower rates of cardiovascular events, cardiovascular and all-cause mortality, and reduced healthcare costs than non-participants, after adjusting for health conditions and behaviors. It was also evident in a subgroup analysis of those who participated in prior screening aided to reduce the bias from the self-selection of healthier participants in screening programs. In addition, screening participation also showed increased outpatient use for hypertension, diabetes mellitus, and dyslipidemia in the following year, explaining the potential pathway of prevention of subsequent cardiovascular disease. The authors acknowledged the inability to fully separate the effect of the screening activities per se in an observational study and the 
possibility of unmeasured confounders that were not fully considered; however, the authors still think that the results are suggestive of a possible true effect of cardiovascular screening on health outcomes [34].

There is a paucity of research on the effects of GHSP on subsequent health behavior. A quasi-experimental study with regression discontinuity design by Kim et al. [71] showed that there is a clear increase in the number of prescribed days of diabetes medication at the 126 cut-off of blood glucose level, which indicates that individuals who are classified as having diabetes mellitus take more diabetes medications during the year or the year after the baseline screening, compared to those who are classified as having prediabetes. The WC also decreased by $0.96 \mathrm{~cm}$ ( $1.1 \%$ change) at the 126 cut-off of blood glucose level, which was mainly driven by behavioral improvement, rather than medications, such as metformin [71]. The author of this study speculated that the change is driven by changes in diet (which was not measured), because they could not find changes in exercise around the cut-off [71]. However, this effect was significant in the short run and decreased to a non-significant level in the long run.

In the same study, they suggested that the information on dyslipidemia (LDL cholesterol $>160$ as a cut-off) increased the number of outpatient visits, but did not translate into increased prescription of medication for dyslipidemia [71]. This is consistent with another Korean study that found only $8.6 \%$ of newly diagnosed hypercholesterolemia patients through the GSHP program received statin prescription within 6 months of diagnosis [112]. The authors speculated that the patients may not consider dyslipidemia less seriously than diabetes mellitus, and non-adherence of clinical practice guidelines by physicians could be the reason for the difference [71].

Another study found that the NSPTA participants who received one-time brief additional counseling were significantly more likely to quit smoking after 2 years; however, the effect size was too small to be considered clinically significant. The authors suggested that repeated counseling might be required to sustain this effect [113].

In summary, these results suggest that participation in a screening program by itself may lead to behavioral changes, at least in the short-term [12,114,115]. However, it might not be sufficient for sustained changes and the improvement of clinical outcomes. This is consistent with the current evidence, which indicates a positive but small benefit of behavioral counseling for the prevention of cardiovascular diseases [116]. Rather, screening can lead to subsequent medical in- terventions, such as medication [117], which may lead to clinical benefits [3].

\section{ISSUES FOR GHSP AND FUTURE DIRECTION}

\section{Need for systematic selection and evaluation of health screening items}

There is criticism that several items in the current GHSP screening do not have scientific evidence. In addition, there is a need to update the program because disease epidemiology is changing; and new technology and evidence are emerging. There is also a great demand from professional societies to include additional items to the GHSP, such as fundoscopic examination (for glaucoma, age-related macular degeneration, etc.) and electrocardiogram (for atrial fibrillation, which was performed until 2008 but was abolished), although it is not firmly based on scientific evidence [118,119].

A systematic evaluation of the overall health screening items was conducted in 2013 [120]. In 2018, the interval for screening for dyslipidemia (lipid profile) was increased from 2 to 4 years. This was based on research on appropriate intervals based on signal-to-noise methods [120] and cost-effectiveness [121]. However, such scientific decisions were faced by fierce objections from medical institutions, as the report should be left blank for that item and difficulties in communication with the participants. Currently, several research projects have been conducted to evaluate the effectiveness or cost-effectiveness, and to identify the optimal strategies for screening in several disease areas [122,123]. The government is preparing a system to ensure the selection and re-evaluation of health screening items and their periodic intervals [21].

\section{Disparity issues regarding GHSP participation}

Participation in health screening has been increasing: the proportion of participants out of the eligible population was $65.4 \%$ in 2008, and increased to 78.5 in 2017, although it slightly decreased in 2018 (76.9\%) and 2019 (74.1\%). Detailed data on participation rates according to age and sex are summarized in Table 3.

However, there is disparity in the income status, region of residence, and disability status. For example, a higher participation rate has been observed with National Health Insurance beneficiaries than medical aid recipients, indicating income inequality [27]. The association between the urbanization level and participation rate was rather complex, and in a 
PRECISION AND FUTURE MIEDICINE

National general health screening program in Korea

Table 3. Participation rates in national General Health Screening Program in Korea: 2008-2019

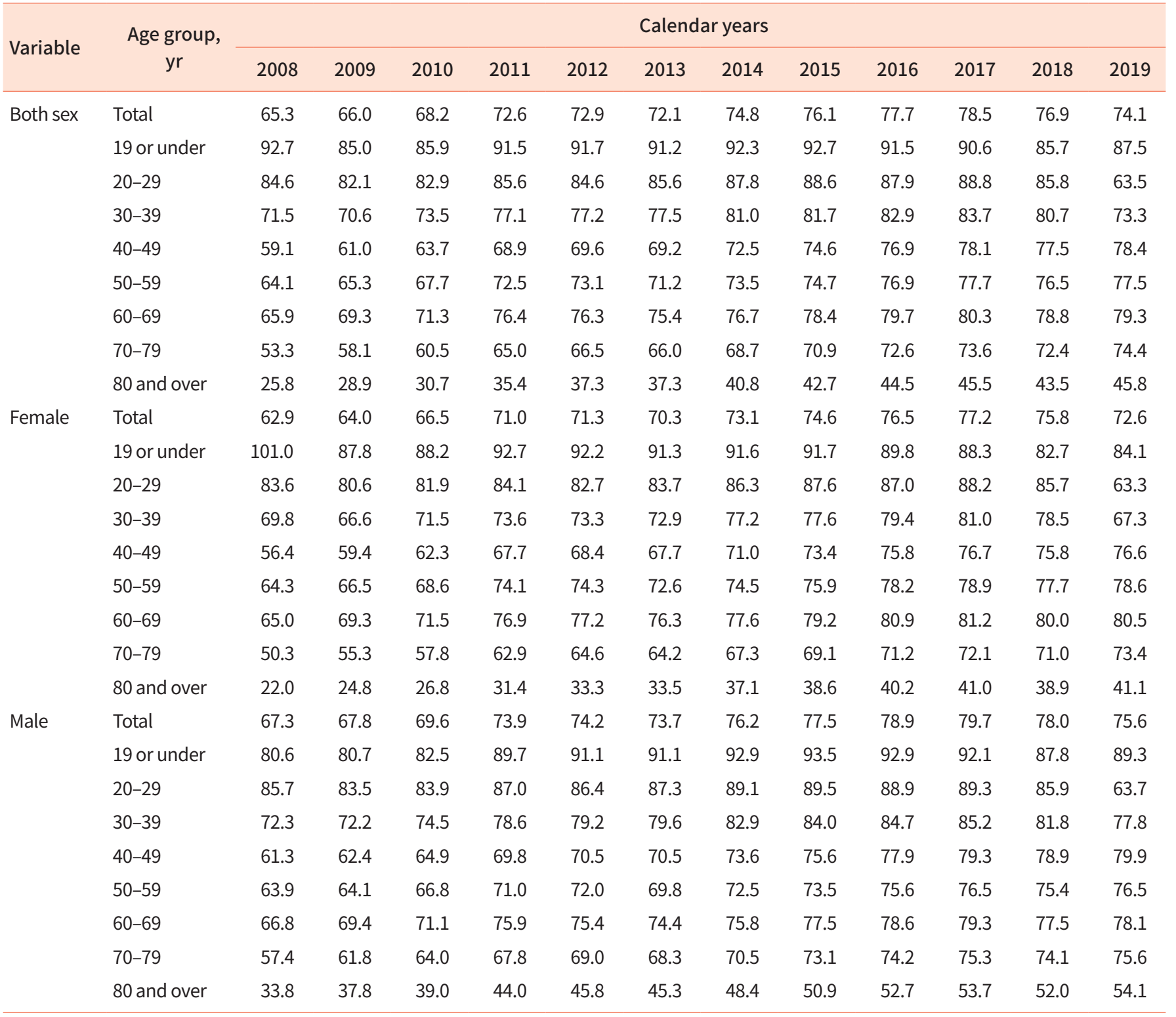

multi-level analysis of the NSPTA program, Yang et al. [124] found that the effect was different with respect to age; that is, higher participation in urban residents at age 40 years and higher participation in rural residents at age 66 years. Differences in the participant characteristics (e.g., employment status) or availability of mobile health screening services (bus equipped with screening services) in rural areas might explain the difference.

It has been reported that individuals with disabilities are less likely to participate in mass screening programs than those without disabilities [125]. According to the 2018 Health Statistics for People with Disabilities, the GHSP participation rates in 2018 were $76.7 \%$ in individuals without disability,
$63.7 \%$ in individuals with mild disability, and $52.3 \%$ in individuals with severe disability [21]. The participation rates also vary by disability type, and people with certain disabilities have difficulty in getting certain health screening tests. For example, individuals with brain injury showed a particularly low screening rate for chest radiography, bone mineral density, and physical function tests. A similar disparity was observed in the case of the NCSP $[76,126]$. Since 2018, the government has designated a health screening center for people with disability. There are criteria for the designations, such as personnel to support communication and transportation, parking lots for people with disabilities, informational material for people with disabilities, etc. There are govern- 
ment subsidies for the designated institutions. Additional payment to medical institutions for provision of health screening to people with severe disability has also commenced in 2019 to promote a safe and convenient environment for them [21]. Further study to elucidate the cause of non-participation is necessary to develop a strategy to reduce disparity in the screening participation.

\section{Linking GSHP to health promotion}

Providing health screening itself is not sufficient to have a positive impact on population health. There is a need to develop aftercare programs and infrastructure at the community and workplace levels, as well as measures to promote referral and participation in this program [21].

The use of information and communication technologybased self-care is another strategy pursued by the government. In 2017, the NHIS launched the "Health IN" mobile application to support self-care of its subscribers (It can be downloadable from the app store: https://play.google.com/ store/apps/details?id = kr.or.nhis. myhealthbank\&hl=ko\&gl $=$ US). Regarding the NHSP, individuals can identify whether they are eligible for each NHSP, find the nearest NHSP provide, and see their health screening results (for the last 10 years) through the application. The health risks calculated from the health screening results are also available from the application. The "Health IN" application can be linked to a wearable device or other health applications, collecting information on physical activity, BP, blood glucose, heart rate, and body temperature. It also provides a push alarm to take medication. An example of use can be found at the NHIS YouTube site (https://www.youtube.com/watch?v=DoU7QHpH$\mathrm{j} 5 \mathrm{w}$, in the Korean Language only). The government is currently preparing a personal health record platform, called 'my healthway,' to enhance the use of health data for health promotion.

\section{CONCLUSION}

In Korea, GHSP has been performed for a long time, and its target population has expanded from workers to encompassing the entire adult population. The main target diseases are cerebro- and cardiovascular diseases, and include hypertension, diabetes mellitus, dyslipidemia, obesity, and related health behaviors. Other target conditions include other diseases (e.g., anemia, liver disease, visual/auditory impairment), mental health (e.g., depression), and geriatric disease and function (osteoporosis, dementia, and risk of fall, etc.).
The NHID, including the GHSP information, is now extensively used in clinical and public health research. A systematic evaluation of the screening items, reduction of disparity gaps in participation, and linking of GHSP to actual health promotion are needed.

\section{CONFLICTS OF INTEREST}

No potential conflict of interest relevant to this article was reported.

\section{ORCID}

Dong Wook Shin $\quad$ https://orcid.org/0000-0001-8128-8920

Juhee Cho https://orcid.org/0000-0001-9081-0266 Jae Hyun Park

BeLong Cho https://orcid.org/0000-0001-5860-7487 https://orcid.org/0000-0001-9558-689X

\section{AUTHOR CONTRIBUTIONS}

Conception or design: DWS, BLC.

Acquisition, analysis, or interpretation of data: DWS, JC, JHP. Drafting the work or revising: DWS, JC, JHP, BLC.

Final approval of the manuscript: DWS, JC, JHP, BLC.

\section{REFERENCES}

1. US Preventive Services Task Force, Krist AH, Davidson KW, Mangione CM, Cabana M, Caughey AB, et al. Screening for hypertension in adults: US Preventive Services Task Force reaffirmation recommendation statement. JAMA 2021; 325:1650-6.

2. US Preventive Services Task Force, Davidson KW, Barry MJ, Mangione CM, Cabana M, Caughey AB, et al. Screening for prediabetes and type 2 diabetes: US Preventive Services Task Force recommendation statement. JAMA 2021;326:736-43.

3. US Preventive Services Task Force, Bibbins-Domingo K, Grossman DC, Curry SJ, Davidson KW, Epling JW Jr, et al. Statin use for the primary prevention of cardiovascular disease in adults: US Preventive Services Task Force recommendation statement. JAMA 2016;316:1997-2007.

4. US Preventive Services Task Force, Curry SJ, Krist AH, Owens DK, Barry MJ, Caughey AB, et al. Screening for osteoporosis to prevent fractures: US Preventive Services Task Force recommendation statement. JAMA 2018;319: 2521-31. 
PRECISION AND FUTURE MIEDICINE

National general health screening program in Korea

5. Siu AL; US Preventive Services Task Force (USPSTF), Bibbins-Domingo K, Grossman DC, Baumann LC, Davidson KW, et al. Screening for depression in adults: US Preventive Services Task Force recommendation statement. JAMA 2016; 315:380-7.

6. US Preventive Services Task Force, Owens DK, Davidson KW, Krist AH, Barry MJ, Cabana M, et al. Screening for hepatitis $C$ virus infection in adolescents and adults: US Preventive Services Task Force recommendation statement. JAMA 2020;323:970-5.

7. US Preventive Services Task Force, Krist AH, Davidson KW, Mangione CM, Barry MJ, Cabana M, et al. Screening for hepatitis B virus infection in adolescents and adults: US Preventive Services Task Force recommendation statement. JAMA 2020;324:2415-22.

8. US Preventive Services Task Force, Bibbins-Domingo K, Grossman DC, Curry SJ, Bauman L, Davidson KW, et al. Screening for latent tuberculosis infection in adults: US Preventive Services Task Force recommendation statement. JAMA 2016;316:962-9.

9. Chung S, Lesser LI, Lauderdale DS, Johns NE, Palaniappan LP, Luft HS. Medicare annual preventive care visits: use increased among fee-for-service patients, but many do not participate. Health Aff (Millwood) 2015;34:11-20.

10. Artac M, Dalton AR, Majeed A, Car J, Millett C. Effectiveness of a national cardiovascular disease risk assessment program (NHS Health Check): results after one year. Prev Med 2013;57:129-34.

11. Dalton AR, Soljak M. The nationwide systematic prevention of cardiovascular disease: the UK's health check programme. J Ambul Care Manage 2012;35:206-15.

12. Kang C, Kawamura A, Noguchi H. Benefits of knowing own health status: effects of health check-ups on health behaviours and labour participation. Appl Econ Lett 2021; 28:926-31.

13. Shin DW, Cho B, Guallar E. Korean national health insurance database. JAMA Intern Med 2016;176:138.

14. Eun BL, Kim SW, Kim YK, Kim JW, Moon JS, Park SK, et al. Overview of the national health screening program for infant and children. Korean J Pediatr 2008;51:225-32.

15. Shin HJ. The current status of the Korean student health examination. Korean J Pediatr 2013;56:313-22.

16. Kim Y, Jun JK, Choi KS, Lee HY, Park EC. Overview of the National Cancer screening programme and the cancer screening status in Korea. Asian Pac J Cancer Prev 2011; 12:725-30.

17. Kang YJ, Myong JP, Eom H, Choi B, Park JH, Kim EAL. The current condition of the workers' general health examination in South Korea: a retrospective study. Ann Occup Environ Med 2017;29:6.

18. World Health Organization, Regional Office for the Western Pacific. Republic of Korea health system review. Manila (PH): WHO Regional Office for the Western Pacific; 2015.

19. Park JS, Lee $\mathrm{CH}$. Clinical study using healthcare claims database. J Rheum Dis 2021;28:119-25.

20. Organisation for Economic Co-operation and Development. OECD Reviews of Public Health: Korea. Paris (FR): OECD;2020.

21. All related Ministries of Government of Republic of Korea. Third-term comprehensive plan for national health screening examinations: 2021-2025. Sejong (KR): Ministries of Government of Republic of Korea; 2021.

22. Lee JY, Jo MW, Yoo WS, Kim HJ, Eun SJ. Evidence of a broken healthcare delivery system in korea: unnecessary hospital outpatient utilization among patients with a single chronic disease without complications. J Korean Med Sci 2014;29:1590-6.

23. Osental D. Private health insurance still booming in South Korea [Internet]. Singapore: Insurance Business (Asia); 2018 [cited 2022 Jan 20]. Available from: https://www. insurancebusinessmag.com/asia/news/breaking-news/ private-health-insurance-still-booming-in-south-korea118259.aspx.

24. Shin DW, Jung KT, Kim S, Bae JM, Kim YW, Ryu KW, et al. Impact of supplementary private health insurance on stomach cancer care in Korea: a cross-sectional study. BMC Health Serv Res 2009;9:133.

25. Kontis V, Bennett JE, Mathers CD, Li G, Foreman K, Ezzati M. Future life expectancy in 35 industrialised countries: projections with a Bayesian model ensemble. Lancet 2017; 389:1323-35.

26. Yang S, Khang YH, Harper S, Davey Smith G, Leon DA, Lynch J. Understanding the rapid increase in life expectancy in South Korea. Am J Public Health 2010;100:896903.

27. Kim HS, Shin DW, Lee WC, Kim YT, Cho B. National screening program for transitional ages in Korea: a new screening for strengthening primary prevention and follow-up care. J Korean Med Sci 2012;27 Suppl:S70-5.

28. Kim YT, Lee WC, Cho B. National screening program for the transitional ages in Korea. J Korean Med Assoc 2010; 53:371-6.

29. The Department of Health (Australia). Lifescripts [Internet]. 
Canberra (AU): The Department of Health (Australia); 2014 [cited 2022 Jan 20]. Available from: https://www1.health. gov.au/internet/main/publishing.nsf/Content/healthpubhlth-strateg-lifescripts-index.htm.

30. Lee WC, Lee SY. National health screening program of Korea. J Korean Med Assoc 2010;53:363-70.

31. Cho B, Lee CM. Current situation of national health screening systems in Korea. J Korean Med Assoc 2011;54:666-9.

32. Korean Law Information Center. Framework act on health examinations [Internet]. Sejong (KR): Korean Law Information Center; 2022 [cited 2022 Jan 20]. Available from: https://www.law.go.kr/LSW/eng/engLsSc.do?menuld=2\&section=lawNm\&query=Framework+act+on+health+ examinations $+\& x=57 \& y=26$.

33. Park SM. Evaluation of the validity of adopting national health screening program for Korean in their twenties and thirties. Seoul (KR): Seoul National University; 2017.

34. Lee H, Cho J, Shin DW, Lee SP, Hwang SS, Oh J, et al. Association of cardiovascular health screening with mortality, clinical outcomes, and health care cost: a nationwide cohort study. Prev Med 2015;70:19-25.

35. Saunders MR, Cifu A, Vela M. Screening for chronic kidney disease. JAMA 2015;314:615-6.

36. Moyer VA; U.S. Preventive Services Task Force. Screening for chronic kidney disease: U.S. Preventive Services Task Force recommendation statement. Ann Intern Med 2012;157:567-70.

37. Qaseem A, Hopkins RH Jr, Sweet DE, Starkey M, Shekelle $\mathrm{P}$; Clinical Guidelines Committee of the American College of Physicians. Screening, monitoring, and treatment of stage 1 to 3 chronic kidney disease: a clinical practice guideline from the American College of Physicians. Ann Intern Med 2013;159:835-47.

38. Siu AL; U.S. Preventive Services Task Force. Screening for iron deficiency anemia and iron supplementation in pregnant women to improve maternal health and birth outcomes: U.S. Preventive Services Task Force recommendation statement. Ann Intern Med 2015;163:529-36.

39. Robalo Nunes A, Mairos J, Brilhante D, Marques F, Belo A, Cortez J, et al. Screening for anemia and iron deficiency in the adult Portuguese population. Anemia 2020;2020: 1048283.

40. Newsome PN, Cramb R, Davison SM, Dillon JF, Foulerton M, Godfrey EM, et al. Guidelines on the management of abnormal liver blood tests. Gut 2018;67:6-19.

41. Yim SY, Kim JH. The epidemiology of hepatitis B virus infection in Korea. Korean J Intern Med 2019;34:945-53.
42. Choi KM, Han K, Park S, Chung HS, Kim NH, Yoo HJ, et al. Implication of liver enzymes on incident cardiovascular diseases and mortality: a nationwide population-based cohort study. Sci Rep 2018;8:3764.

43. Chung GE, Cho EJ, Yoon JW, Yoo JJ, Chang Y, Cho Y, et al. Nonalcoholic fatty liver disease increases the risk of diabetes in young adults: a nationwide population-based study in Korea. Metabolism 2021;123:154866.

44. Song JH, Huh K, Chung DR. Modern history of tuberculosis in Korea. Infect Chemother 2019;51:414-26.

45. Han G, Han J, Han K, Chung TY, Na KS, Lim DH. Relationships among visual acuity, risk of acute myocardial infarction, and stroke: a nationwide cohort study in South Korea. Ophthalmic Epidemiol 2021:1-13.

46. Yi HJ, Kim HJ, Suh M. Clinical validity of the national hearing screening method for transitional ages: a proposal of accurate screening for early hearing loss detection. J Clinical Otolaryngol 2020;31:37-44.

47. Kim S, Park JM, Han JS, Seo JH, Han KD, Joo YH, et al. Age-related hearing loss in the Korea National Health and Nutrition Examination Survey. PLoS One 2020;15:e0243001.

48. US Preventive Services Task Force (USPSTF), Siu AL, Bibbins-Domingo K, Grossman DC, Baumann LC, Davidson $\mathrm{KW}$, et al. Screening for impaired visual acuity in older adults: US Preventive Services Task Force recommendation statement. JAMA 2016;315:908-14.

49. US Preventive Services Task Force, Krist AH, Davidson KW, Mangione CM, Cabana M, Caughey AB, et al. Screening for hearing loss in older adults: US Preventive Services Task Force recommendation statement. JAMA 2021;325:1196201.

50. Organisation for Economic Co-operation and Development. Health at a Glance 2019. Paris (FR): OECD; 2019.

51. Lee SU, Park JI, Lee S, Oh IH, Choi JM, Oh CM. Changing trends in suicide rates in South Korea from 1993 to 2016: a descriptive study. BMJ Open 2018;8:e023144.

52. Cho MJ, Kim KH. Use of the Center for Epidemiologic Studies Depression (CES-D) scale in Korea. J Nerv Ment Dis 1998; 186:304-10.

53. Bae JN, Cho MJ. Development of the Korean version of the Geriatric Depression Scale and its short form among elderly psychiatric patients. J Psychosom Res 2004;57: 297-305.

54. Kroenke K, Spitzer RL, Williams JB. The PHQ-9: validity of a brief depression severity measure. J Gen Intern Med 2001;16:606-13.

55. Kocalevent RD, Hinz A, Brahler E. Standardization of the 
PRECISION AND FUTURE MIEDICINE

National general health screening program in Korea

depression screener patient health questionnaire (PHQ9) in the general population. Gen Hosp Psychiatry 2013;35: 551-5.

56. Han C, Jo SA, Kwak JH, Pae CU, Steffens D, Jo I, et al. Validation of the Patient Health Questionnaire-9 Korean version in the elderly population: the Ansan Geriatric study. Compr Psychiatry 2008;49:218-23.

57. Jeon YG, Yun KE, Kim YS. Validation of KDSQ-P as selecting elderly for KDSQ-C. Korean J Health Promot 2010;10: 45-52.

58. Yang DW, Cho BL, Chey JY, Kim SY, Kim BS. The development and validation of Korean Dementia Screening Questionnaire (KDSQ). J Korean Neurol Assoc 2002;20:135-41.

59. Jung HW, Kim S, Jang IY, Shin DW, Lee JE, Won CW. Screening value of timed up and go test for frailty and low physical performance in Korean older population: the Korean Frailty and Aging Cohort Study (KFACS). Ann Geriatr Med Res 2020;24:259-66.

60. Barry E, Galvin R, Keogh C, Horgan F, Fahey T. Is the Timed Up and Go test a useful predictor of risk of falls in community dwelling older adults: a systematic review and meta-analysis. BMC Geriatr 2014;14:14.

61. Jeong SM, Shin DW, Han K, Jung JH, Chun S, Jung HW, et al. Timed up-and-go test is a useful predictor of fracture incidence. Bone 2019;127:474-81.

62. Lee JE, Shin DW, Jeong SM, Son KY, Cho B, Yoon JL, et al. Association between Timed Up and Go test and future dementia onset. J Gerontol A Biol Sci Med Sci 2018;73:123843.

63. Yoo JE, Jang W, Shin DW, Jeong SM, Jung HW, Youn J, et al. Timed Up and Go test and the risk of Parkinson's disease: a nation-wide retrospective cohort study. Mov Disord 2020;35:1263-7.

64. Chun S, Shin DW, Han K, Jung JH, Kim B, Jung HW, et al. The Timed Up and Go test and the ageing heart: findings from a national health screening of $1,084,875$ community-dwelling older adults. Eur J Prev Cardiol 2021;28:2139.

65. Chun SH, Cho B, Yang HK, Ahn E, Han MK, Oh B, et al. Performance on physical function tests and the risk of fractures and admissions: findings from a national health screening of 557,648 community-dwelling older adults. Arch Gerontol Geriatr 2017;68:174-80.

66. Won CW, Yang KY, Rho YG, Kim SY, Lee EJ, Yoon JL, et al. The development of Korean activities of daily living (K-ADL) and Korean instrumental activities of daily living (K-IADL) scale. J Korean Geriatr Soc 2002;6:107-20.
67. Lee JA, Oh MJ, Son KY, Cho B. Evaluation system of quality assurance in the national health screening institution: toward better performance. Qual Improv Health Care 2011;17:37-43.

68. Ministry of Health and Welfare. Guidance for the National Health Screening Program, 2021. Sejong (KR): Ministry of Health and Welfare; 2021.

69. Lee SW, Lee HY, Ihm SH, Park SH, Kim TH, Kim HC. Status of hypertension screening in the Korea National General Health Screening Program: a questionnaire survey on 210 screening centers in two metropolitan areas. Clin Hypertens 2017;23:23.

70. Jeong WK, Lee EH, Jung SE. Quality management of medical imaging for public health screening. J Korean Med Assoc 2015;58:1125-31.

71. Kim HB, Lee SA, Lim W. Knowing is not half the battle: impacts of information from the National Health Screening Program in Korea. J Health Econ 2019;65:1-14.

72. Park JH, Kwon H, Oh SW, Lee CM, Cho B. Update and validation of a national health risk appraisal tool in Korea. J Public Health (Oxf) 2013;35:107-14.

73. Kim JY, Park BJ, Kim Y, Park JH, Cho BL. Predictive accuracy of a health risk appraisal program using mortality risk age in 116,927 Korean men. J Korean Med Sci 2011; 26:159-65.

74. Cho B. Improvement of Health Risk Appraisal (HRA). Seoul (KR): Seoul National University; 2017.

75. Yun JM, Yoo TG, Oh SW, Cho BL, Kim E, Hwang I. Prediction of cardiovascular disease in Korean population: based on health risk appraisal of national health screening program. J Korean Med Assoc 2017;60:746-52.

76. Shin DW, Lee JW, Jung JH, Han K, Kim SY, Choi KS, et al. Disparities in cervical cancer screening among women with disabilities: a national database study in South Korea. J Clin Oncol 2018;36:2778-86.

77. Lee S. Social security system of South Korea: Technical Note IDB-TN-872 [Internet]. Washington (DC): Inter-American Development Bank; 2015 [cited 2022 Jan 20]. Available from: https://publications.iadb.org/publications/ english/document/Social-Security-System-of-South-Korea. pdf.

78. Shin DW, Cho J, Kim SY, Guallar E, Hwang SS, Cho B, et al. Delay to curative surgery greater than 12 weeks is associated with increased mortality in patients with colorectal and breast cancer but not lung or thyroid cancer. Ann Surg Oncol 2013;20:2468-76.

79. Lee J, Lee JS, Park SH, Shin SA, Kim K. Cohort profile: 
the National Health Insurance Service-National Sample Cohort (NHIS-NSC), South Korea. Int J Epidemiol 2017; 46:e15.

80. Seong SC, Kim YY, Park SK, Khang YH, Kim HC, Park JH, et al. Cohort profile: the National Health Insurance Service-National Health Screening Cohort (NHIS-HEALS) in Korea. BMJ Open 2017;7:e016640.

81. Kim YI, Kim YY, Yoon JL, Won CW, Ha S, Cho KD, et al. Cohort profile: national health insurance service-senior (NHIS-senior) cohort in Korea. BMJ Open 2019;9:e024344.

82. Won TY, Kang BS, Im TH, Choi HJ. The study of accuracy of death statistics. J Korean Soc Emerg Med 2007;18:25662.

83. Kim YY, Hong HY, Cho KD, Park JH. Family tree database of the National Health Information Database in Korea. Epidemiol Health 2019;41:e2019040.

84. Seong SC, Kim YY, Khang YH, Park JH, Kang HJ, Lee H, et al. Data resource profile: the National Health Information Database of the National Health Insurance Service in South Korea. Int J Epidemiol 2017;46:799-800.

85. Kim JA, Yoon S, Kim LY, Kim DS. Towards actualizing the value potential of Korea Health Insurance Review and Assessment (HIRA) data as a resource for health research: strengths, limitations, applications, and strategies for optimal use of HIRA data. J Korean Med Sci 2017;32:71828.

86. Kim HK, Song SO, Noh J, Jeong IK, Lee BW. Data configuration and publication trends for the Korean National Health Insurance and Health Insurance Review \& Assessment Database. Diabetes Metab J 2020;44:671-8.

87. Kim I, Bahk J, Kim YY, Lee J, Kang HY, Lee J, et al. Comparison of district-level smoking prevalence and their income gaps from two national databases: the National Health Screening Database and the Community Health Survey in Korea, 2009-2014. J Korean Med Sci 2018;33:e44.

88. Seo MH, Kim YH, Han K, Jung JH, Park YG, Lee SS, et al. Prevalence of obesity and incidence of obesity-related comorbidities in Koreans based on National Health Insurance Service health checkup data 2006-2015. J Obes Metab Syndr 2018;27:46-52.

89. Yoo JE, Shin DW, Han K, Kim D, Jeong SM, Koo HY, et al. Association of the frequency and quantity of alcohol consumption with gastrointestinal cancer. JAMA Netw Open 2021;4:e2120382.

90. Chang Y, Yoo JJ, Cho EJ, Han K, Kim D, Kim BY, et al. Weight fluctuation and risk of hepatocellular carcinoma: a nationwide population-based 8-million-subject study. Hepatol
Int 2021;15:482-92.

91. Jeong SM, Choi T, Kim D, Han K, Kim SJ, Rhee SY, et al. Association between high-density lipoprotein cholesterol level and risk of hematologic malignancy. Leukemia 2021;35:1356-64.

92. Yoo JE, Shin DW, Han K, Kim D, Lee SP, Jeong SM, et al. Blood pressure variability and the risk of dementia: a nationwide cohort study. Hypertension 2020;75:982-90.

93. Jeong SM, Han K, Kim D, Rhee SY, Jang W, Shin DW. Body mass index, diabetes, and the risk of Parkinson's disease. Mov Disord 2020;35:236-44.

94. Eun Y, Jeon KH, Han K, Kim D, Kim H, Lee J, et al. Menopausal factors and risk of seropositive rheumatoid arthritis in postmenopausal women: a nationwide cohort study of 1.36 million women. Sci Rep 2020;10:20793.

95. Cho IY, Han K, Shin DW, Park SH, Yoon DW, Shin S, et al. Cardiovascular risk and undertreatment of dyslipidemia in lung cancer survivors: a nationwide population-based study. Curr Probl Cancer 2021;45:100615.

96. Kang J, Jeong SM, Shin DW, Cho M, Cho JH, Kim J. The associations of aspirin, statins, and metformin with lung cancer risk and related mortality: a time-dependent analysis of population-based nationally representative data. J Thorac Oncol 2021;16:76-88.

97. Kim NH, Han KH, Choi J, Lee J, Kim SG. Use of fenofibrate on cardiovascular outcomes in statin users with metabolic syndrome: propensity matched cohort study. BMJ 2019;366:15125.

98. Nam GE, Kim YH, Han K, Jung JH, Park YG, Lee KW, et al. Obesity fact sheet in Korea, 2018: data focusing on waist circumference and obesity-related comorbidities. J Obes Metab Syndr 2019;28:236-45.

99. Nam GE, Kim YH, Han K, Jung JH, Rhee EJ, Lee SS, et al. Obesity fact sheet in Korea, 2019: prevalence of obesity and abdominal obesity from 2009 to 2018 and social factors. J Obes Metab Syndr 2020;29:124-32.

100. Choi EK. Cardiovascular research using the Korean National Health Information Database. Korean Circ J 2020;50: 754-72.

101. Shin DW, Suh B, Lim H, Suh YS, Choi YJ, Jeong SM, et al. Increased risk of osteoporotic fracture in postgastrectomy gastric cancer survivors compared with matched controls: a nationwide cohort study in Korea. Am J Gastroenterol 2019;114:1735-43.

102. Shin DW, Suh B, Lim H, Yun JM, Song SO, Park Y. J-shaped association between postoperative levothyroxine dosage and fracture risk in thyroid cancer patients: a retro- 
PRECISION AND FUTURE MIEDICINE

National general health screening program in Korea

spective cohort study. J Bone Miner Res 2018;33:1037-43.

103. Kimm H, Yun JE, Lee SH, Jang Y, Jee SH. Validity of the diagnosis of acute myocardial infarction in Korean national medical health insurance claims data: the Korean heart study (1). Korean Circ J 2012;42:10-5.

104. Choi YJ, Choi EK, Han KD, Jung JH, Park J, Lee E, et al. Temporal trends of the prevalence and incidence of atrial fibrillation and stroke among Asian patients with hypertrophic cardiomyopathy: a nationwide populationbased study. Int J Cardiol 2018;273:130-5.

105. Yoo JE, Kim D, Han K, Rhee SY, Shin DW, Lee H. Diabetes status and association with risk of tuberculosis among Korean adults. JAMA Netw Open 2021;4:e2126099.

106. Jeong SM, Jeon KH, Shin DW, Han K, Kim D, Park SH, et al. Smoking cessation, but not reduction, reduces cardiovascular disease incidence. Eur Heart J 2021;42:414153.

107. Park JB, Kim DH, Lee H, Lee HJ, Hwang IC, Yoon YE, et al. Effect of moderately but persistently elevated lipid levels on risks of stroke and myocardial infarction in young Korean adults. J Am Heart Assoc 2021;10:e020050.

108. Lee YB, Kim DH, Kim SM, Kim NH, Choi KM, Baik SH, et al. Risk of type 2 diabetes according to the cumulative exposure to metabolic syndrome or obesity: a nationwide population-based study. J Diabetes Investig 2020; 11:1583-93.

109. Cho EJ, Han K, Lee SP, Shin DW, Yu SJ. Liver enzyme variability and risk of heart disease and mortality: a nationwide population-based study. Liver Int 2020;40:1292302.

110. Krogsboll LT, Jorgensen KJ, Gronhoj Larsen C, Gotzsche PC. General health checks in adults for reducing morbidity and mortality from disease: Cochrane systematic review and meta-analysis. BMJ 2012;345:e7191.

111. Jorgensen T, Jacobsen RK, Toft U, Aadahl M, Glumer C, Pisinger C. Effect of screening and lifestyle counselling on incidence of ischaemic heart disease in general population: Inter99 randomised trial. BMJ 2014;348:g3617.

112. Ahn E, Shin DW, Yang HK, Yun JM, Chun SH, Suh B, et al. Treatment gap in the national health-screening program in Korea: claim-based follow-up of statin use for sustained hypercholesterolemia. J Korean Med Sci 2015;30:1266-72.

113. Son KY, Shin DW, Yang HK, Yun JM, Chun SH, Lee JK, et al. Effect of one-time brief additional counseling on periodic health examination for 40- and 66-year-olds: 2-year follow up of 101260 participants. Geriatr Gerontol Int 2018; 18:329-37.
114. Zhao M, Konishi Y, Glewwe P. Does information on health status lead to a healthier lifestyle? Evidence from China on the effect of hypertension diagnosis on food consumption. J Health Econ 2013;32:367-85.

115. Oster E. Diabetes and diet: purchasing behavior change in response to health information. Am Econ J Appl Econ 2018;10:308-48.

116. US Preventive Services Task Force, Grossman DC, Bibbins-Domingo K, Curry SJ, Barry MJ, Davidson KW, et al. Behavioral counseling to promote a healthful diet and physical activity for cardiovascular disease prevention in adults without cardiovascular risk factors: US Preventive Services Task Force recommendation statement. JAMA 2017;318:167-74.

117. Kaczorowski J, Chambers LW, Dolovich L, Paterson JM, Karwalajtys T, Gierman T, et al. Improving cardiovascular health at population level: 39 community cluster randomised trial of Cardiovascular Health Awareness Program (CHAP). BMJ 2011;342:d442.

118. US Preventive Services Task Force, Curry SJ, Krist AH, Owens DK, Barry MJ, Caughey AB, et al. Screening for atrial fibrillation with electrocardiography: US Preventive Services Task Force recommendation statement. JAMA 2018;320:478-84.

119. Moyer VA; U.S. Preventive Services Task Force. Screening for glaucoma: U.S. Preventive Services Task Force recommendation statement. Ann Intern Med 2013;159:4849.

120. Cho B. Evaluation of the validity of current national health screening programs and plans to improve the system. Seoul (KR): Seoul National University; 2013.

121. Park S, Park EC, Nam CM, Lee SH, Kim TH, Lee KS. Cost-effectiveness analysis for National Lipid Disorders Screening Program. Seoul (KR): Yonsei University; 2014.

122. Lee HY, Lee SW, Kim HC, Ihm SH, Park SH, Kim TH. Costeffectiveness analysis of hypertension screening in the Korea National Health Screening Program. Korean Circ J 2021;51:610-22.

123. Kim JH, Park EC, Kim TH, Nam CM, Chun SY, Lee TH, et al. Cost-effectiveness analysis for national dyslipidemia screening program in Korea: results of best case scenario analysis using a Markov model. Health Policy Manage 2019;29:357-67.

124. Yang HK, Shin DW, Hwang SS, Oh J, Cho BL. Regional factors associated with participation in the national health screening program: a multilevel analysis using national data. J Korean Med Sci 2013;28:348-56. 
PRECISION AND FUTURE MIEDICINE

Dong Wook Shin, et al.

125. Park JH, Lee JS, Lee JY, Gwack J, Park JH, Kim YI, et al. Disparities between persons with and without disabilities in their participation rates in mass screening. Eur $\mathrm{J}$ Public Health 2009;19:85-90.
126. Shin DW, Yu J, Cho J, Lee SK, Jung JH, Han K, et al. Breast cancer screening disparities between women with and without disabilities: a national database study in South Korea. Cancer 2020;126:1522-9. 